\title{
INTERFACIAL FRICTION IN GAS-LIQUID ANNULAR FLOW: ANALOGIES TO FULL AND TRANSITION ROUGHNESS
}

L. B. Fore

S. G. Beus

R. C. Bauer
RECEIVED

APR $0 \div 1999$

OSTI

\section{NOTICE}

This report was prepared as an account of work sponsored by the United States Government. Neither the United States, nor the United States Department of Energy, nor any of their employees, nor any of their contractors, subcontractors, or their employees, makes any warranty, express or implied, or assumes any legal liability or responsibility for the accuracy, completeness or usefulness of any information, apparatus, product or process disclosed, or represents that its use would not infringe privately owned rights. 
B-T-3258

Page 2

INTENTIONALLY BLANK PAGE 


\section{DISCLAIMER}

This report was prepared as an account of work sponsored by an agency of the United States Government. Neither the United States Government nor any agency thereof, nor any of their employees, make any warranty, express or implied, or assumes any legal liability or responsibility for the accuracy, completeness, or usefulness of any information, apparatus, product, or process disclosed, or represents that its use would not infringe privately owned rights. Reference herein to any specific commercial product, process, or service by trade name, trademark, manufacturer, or otherwise does not necessarily constitute or imply its endorsement, recommendation, or favoring by the United States Government or any agency thereof. The views and opinions of authors expressed herein do not necessarily state or reflect those of the United States Government or any agency thereof. 


\section{DISCLAIMER}

Portions of this document may be illegible in electronic image products. Images are produced from the best available original document. 


\section{Abstract}

New film thickness and pressure gradient data were obtained in a 5.08 by $101.6 \mathrm{~mm}$ duct for nitrogen and water in annular flow. Pressures of 3.4 and 17 atm and temperatures of 38 and $93^{\circ} \mathrm{C}$ were used to vary the gas density and liquid viscosity. These data are used to compute interfacial shear stresses and interfacial friction factors for comparison with several accepted literature correlations. These comparisons are reasonable for small values of the relative film thickness. However, the new data cover conditions not approached by the data used to construct those correlations. By combining the current data with the results of two other comprehensive modern experimental studies, a new correlation for the interfacial friction factor has been developed. This correlation adds elements of transition roughness to Wallis' fully-rough analogy to better predict interfacial friction factors over a wide range of gas Reynolds numbers and liquid film thicknesses. 
B-T-3258

Page 4

INTENTIONALLY BLANK PAGE 


\section{INTRODUCTION}

Gas-liquid annular flow is one of the most common two-phase flow patterns that arise in practice. It is characterized by a thin liquid film distributed around the perimeter of a conduit, with a mixture of gas and droplets in the core region of the conduit. The presence of the liquid film and droplets modify the gas velocity profile from the flattened profile expected in single-phase turbulent flow to a more center-peaked profile (Gill, et al., 1964; Jayawardena, 1993; Azzopardi \& Teixeira, 1994). The power-law coefficient of the velocity profile, defined as $n$ in

$$
\frac{u}{u_{c}}=\left(\frac{2 y}{D}\right)^{1 / n}
$$

where $u$ is the axial velocity, $u_{c}$ is the axial velocity at the centerline and $y$ is the distance from the wall, can be significantly smaller than the typical single-phase value of $n=7$ for smooth conduits. This corresponds to a larger friction factor than for the analogous single-phase flow, since

$$
f \approx \frac{1}{4 n^{2}}
$$

according to Nunner's results (Hinze, 1975). When the velocity-defect law,

$$
\frac{u_{c}-u}{u^{*}}=\frac{1}{\kappa} \ln \left(\frac{2 y}{D}\right)
$$

is used to characterize the velocity profile, a smaller value of the von Karman constant, $\kappa$, is also found. Single-phase turbulent flow in rough tubes exhibits these same characteristics, with roughness decreasing the power-law coefficient and von Karman constant while increasing the friction factor and pressure drop.

Since pressure drop is one of the most important parameters used to characterize a flow system, several methods have been proposed to model or correlate the friction factors in annular flow. Wallis (1969) suggested a correlation which treats the liquid film as a type of wall roughness. He originally fit four sets of annular flow data using the ratio of mean film thickness to conduit hydraulic diameter with the relation

$$
f_{i}=0.005\left(1+300 \frac{h}{D}\right)
$$

He then noted the similarity to the relationship,

$$
f=0.005\left(1+75 \frac{k_{s}}{D}\right)
$$

where $k_{s}$ is the Nikuradse sand-grain roughness height. The relationship (5) approximates the behavior of fully rough friction factors for values of $k_{s} / D$ less than approximately 0.03 . This result implied that the sand-grain roughness was 
approximately four times the mean film thickness for the conditions used to construct the correlation.

The Wallis correlation has been modified over the years, with some finding a better fit to data by using a computed single-phase gas friction factor, $f_{G}$, in place of the constant 0.005 , as

$$
f_{i}=f_{G}\left(1+300 \frac{h}{D}\right)
$$

However, this relationship no longer approximates fully rough friction factors, which should be independent of the Reynolds number from which $f_{G}$ is calculated. Additionally, neither equation (4) nor (6) accurately predicts the behavior of thicker films in a number of studies reported in the literature. Various explanations have been suggested for the deviation at large film thicknesses. For many studies, the larger film thicknesses correspond to smaller gas flow rates and corresponding gas Reynolds numbers. This fact, and some analysis of Zabaras' (1985) film thickness and pressure drop data, led Lopes \& Dukler (1986) to suggest transition roughness, as opposed to full roughness, as the mechanism for the enhanced friction factor at smaller gas Reynolds numbers and larger film thicknesses. To this point, however, this idea has not been pursued substantially further.

Several correlations have been proposed to better predict the behavior of the friction factors for large film thicknesses that has sometimes been observed. Henstock \& Hanratty (1977) and Asali, et al. (1985) developed correlations to account for the deviation of some measured friction factors from the Wallis, or modified Wallis, correlation. Practically all of the data used to develop these correlations were obtained under relatively low pressures. This paper presents new measurements obtained at higher pressures which can be used in conjunction with existing published data to better understand and account for the behavior of the interfacial friction factor at low Reynolds numbers. A new correlation is developed, based on the analogy to transition roughness, to obtain better predictions over a fuller range of Reynolds numbers than represented by existing correlations.

\section{EXPERIMENTAL}

\section{Flow Loop}

Figure 1 is a schematic of the test section and flow loop used to obtain the new measurements presented in this paper. Both gas and liquid flow systems were operated as closed loops. A large separator tank was used as a loop pressurizer and as the reservoir for gas and liquid. A centrifugal pump was used to circulate water from the separator, through a pair of Endress-Hauser Promass model 63F Coriolis flow meters installed in series, and to the test section liquid entry section. A reciprocating compressor was used to circulate nitrogen from the separator, through a pair of Rosemount model 8800 vortex flow meters installed in series, and to the test section gas inlet piping. The manufacturer-stated accuracies of the water and gas flow meters were $\pm 2 \%$ and $\pm 1 \%$, respectively. A gas heater was used to control the nitrogen temperature and several water heaters were used to control the water temperature. The system pressure was controlled by a pressure-regulated nitrogen supply attached to the 
top portion of the loop separator. Temperatures, measured with chromel-alumel thermocouples, are considered accurate within $\pm 2^{\circ} \mathrm{C}$ and system gage pressures, measured with Rosemount Model $3051 \mathrm{C}$ pressure transmitters, are considered accurate within $\pm 1 \%$.

\section{Test Section and Measurement Techniques}

The test section was a 5.08 by $101.6 \mathrm{~mm}$ by $3.4-\mathrm{m}$-long rectangular duct constructed of 304 stainless steel. The liquid feed in the test section was made up of two porous sections of the side walls and the gas feed was made up of an axial length of piping attached to the bottom of the test section. The gas and liquid exited through two porous wall sections near the top of the test section and through an axial length of piping attached to the top of the test section. Three pairs of fused-silica windows, including one large pair, were installed in the test section for flow observation. All measurements, as described below, were made between the liquid entry section and the pair of large observation windows.

Pressure taps were located at nine locations between the liquid entry section and the observation window along a vertical line displaced $2.54 \mathrm{~cm}$ from the center of the $101.6 \mathrm{~mm}$ wide wall. The tap locations were at positions $10.8,28.6,46.4,64.0,81.9$, 99.7, 117.5, 135.3 and $153 \mathrm{~cm}$ above the liquid entry section. Eight pressure drop measurements were made with Rosemount Model 3051C differential pressure transmitters between the lowest pressure tap and each of the taps located above it (from 10.8 to $28.6 \mathrm{~cm}, 10.8$ to $46.4 \mathrm{~cm}$, etc.). Each of these measurements is considered accurate within $\pm 1 \%$. All differential pressures were digitized at 3 samples per second and digitally filtered to smooth out the time-dependent fluctuations. The time required to reach steady time-smoothed values of differential pressure depended on flow conditions. The time series of the smoothed differential pressures were observed until they reached steady values, at which time each was recorded to disk along with the flow rates, miscellaneous temperatures and system gage pressures.

Film thickness probes were located at the same axial locations as the pressure taps along a vertical line at the center of the $101.6 \mathrm{~mm}$ side wall. The film thickness probes were constructed of $6.35 \mathrm{~mm}$ diameter cylindrical Teflon inserts with $1.59 \mathrm{~mm}$ diameter chromel wires imbedded along the insert axis to form a coaxial conductorinsulator arrangement mounted flush with the test section wall. The conductance of the liquid film above the probes and between the face of the chromel wire and the test section wall was measured with a circuit similar to that described by Coney (1973) and related to the film thickness through a calibration. A conductivity reference probe was installed in the liquid lines leading to the test section and used to compensate for temperature and concentration-dependent variations in electrical conductivity. With the curved surface of a small diameter tube, there is an ambiguity in the measured film thickness when using local flush-mounted probes. This ambiguity arises from the difficulty in calibration, which requires the artificial formation of a series of thin annular films by the use of machined rod inserts. The gap between the rod and tube wall is difficult to know precisely, particularly for very small gaps. This potential error is eliminated when the film probes are mounted in flat walls, since the artificial film can be formed by precisely positioning a second flat surface above the probe. This type of calibration was performed in the current study, with the position of the second flat surface measured using a precision micrometer. Assuming the conductivity variation is 
properly accounted for, the calibration accuracy of $\pm 0.02 \mathrm{~mm}$ represents a conservative estimate of the accuracy of a single film thickness probe.

The output voltages of the conditioning circuit for eight of the nine film probes (all probes except that located at $81.9 \mathrm{~cm}$ ) and the conductivity reference probe were digitized at 2000 samples per second for 60 seconds. The output voltages were converted to film thickness and a mean value calculated for each probe. Since the film thickness did not vary systematically from probe to probe, the values associated with the upper seven probes were averaged together to reduce the uncertainty associated with an individual film thickness probe measurement.

The entrained liquid fraction was estimated by withdrawing the liquid film through a porous wall section located above the ninth film thickness probe and collecting the entrained droplets with a traversing sampling probe of diameter $1.57 \mathrm{~mm}$ similar to that used by Asali (1984). The deposition rate was estimated by repeating this measurement with a second traversing probe located $0.307 \mathrm{~m}$ downstream. The reduction of droplet flow from the first probe to the second is directly related to the deposition rate of the droplets onto the wall. Neither of the two sampling probes was operated in an isokinetic manner, which has been shown to be unnecessary by Asali and others for the measurement of annular flow droplet flux. The accuracies of the entrained fraction and deposition rate measurement were estimated at $\pm 5 \%$ and $\pm 10 \%$.

\section{Test Conditions}

Film thickness and pressure gradient data were collected for nitrogen-water annular flow at 136 different operating conditions. Two nominal system pressures, 3.4 and $17 \mathrm{~atm}$, and two nominal temperatures, 38 and $93^{\circ} \mathrm{C}$ were used to produce four pressure-temperature combinations. The range of superficial gas velocity at each temperature was 5 to $30 \mathrm{~m} / \mathrm{s}$ at $p=3.4$ atm and 4 to $20 \mathrm{~m} / \mathrm{s}$ at $p=17$ atm. The range of superficial liquid velocity was 0.06 to $1.0 \mathrm{~m} / \mathrm{s}$ for all combinations of pressure and temperature.

\section{MOMENTUM BALANCE ANALYSIS AND FRICTION FACTORS}

The interfacial friction factor in annular flow is typically defined by

$$
f_{i}=\frac{2 \tau_{i}}{\rho_{G} U_{G}^{2}},
$$

where $\tau_{i}$ is the interfacial shear stress, $\rho_{G}$ is the gas density and $U_{G}$ is the mean gas velocity in the gas-droplet core. In some cases, the core gas-droplet density and the superficial gas velocity have been used in an alternate definition of the interfacial friction factor. The interfacial shear stress is computed with a momentum balance applied in the axial direction on the gas-droplet core (Moeck \& Stachiewicz, 1972; Lopes \& Dukler, 1986; Fore \& Dukler, 1995a). For a number of data sets in the literature, there is significant gas expansion present in the experiments, which accounts for some fraction of the total pressure drop. Neglecting this effect adds a positive bias to the computed value of the interfacial shear stress and to the interfacial friction factor. The following momentum balance analysis is slightly different from those presented by Lopes \& Dukler and Fore \& Dukler, in that an estimate of the gas expansion effect is included. 
Figure 2 is a schematic of the gas-droplet core of a typical adiabatic annular flow. The control volume used for the momentum balance is bounded by the film on the sides parallel to the axial direction and by planes spaced an arbitrary distance apart normal to the axial direction. At steady state, the Reynolds transport theorem in the axial direction over this control volume is written

$$
\int_{A} u_{z} \rho_{c} u_{z} d A=\int_{A} T_{z} d A+\int_{V} B_{z} d V
$$

where $u_{z}$ is the local axial velocity, $\rho_{c}$ is the core mixture density, $T_{z}$ is the axially-directed surface force per unit area and $B_{z}$ is the axial body force per unit volume.

Under true equilibrium conditions, the convective integral on the left hand side of equation (8) consists solely of the momentum changes caused by the entrainmentdeposition process, in which faster moving drops deposit out of the control volume and slower moving drops entrain into the control volume. When there is significant gas expansion or a change in entrainment within the control volume, another term is added to the convective integral. Using $A_{c}$ as the cross sectional area of the control volume and $P_{C}$ as the perimeter, the convective integral can be approximated as

$$
\int_{A} u_{z} \rho_{c} u_{z} d A=A_{c} d\left(\rho_{c} U_{z}^{2}\right)+P_{c} d z\left(R_{D} U_{D}-R_{E} U_{E}\right)
$$

where $R_{E}$ is the entrainment rate, $R_{D}$ is the deposition rate, $U_{z}$ is the mean axial velocity in the control volume, $U_{E}$ is the mean axial velocity of entraining drops and $U_{D}$ is the mean axial velocity of depositing drops. The surface force integral consists of the interfacial shear stress, $\tau_{i}$, and applied pressure, $p$, while the body force integral consists of the gravity force on the gas and droplets as

$$
\int_{A} T_{z} d A=-P_{C} d z \tau_{i}-A_{C} d p
$$

and

$$
\int_{V} B_{z} d V=-A_{c} d z \rho_{c} g
$$

Combining and simplifying the various terms results in

$$
\tau_{i}=-\frac{A_{c}}{P c}\left(\frac{d p}{d z}+\frac{d}{d z}\left(\rho_{c} U_{z}^{2}\right)+\rho_{c} g\right)-R_{D} U_{D}+R_{E} U_{E}
$$

The derivative of the axial momentum flux can be evaluated with a few assumptions, using the definition

$$
\rho_{c} U_{z} A_{c}=W_{G}+W_{L E}
$$


where $W_{G}$ is the gas mass flow rate and $W_{L E}$ is the entrainment mass flow rate. Without evaporation or condensation, $W_{G}$ is constant but $W_{L E}$ can still vary due to nonequilibrium entrainment-deposition conditions. The derivative of the axial momentum flux can then be evaluated as

$$
\frac{d}{d z}\left(\rho_{c} U_{z}^{2} A_{c}\right)=\frac{d}{d z}\left[\left(W_{G}+W_{L E}\right) U_{z}\right]=W_{G} \frac{d U_{z}}{d z}+W_{L E} \frac{d U_{z}}{d z}+U_{z} \frac{d W_{L E}}{d z}
$$

The axial derivative of the velocity can be evaluated with the pressure gradient, assuming that the droplets and gas travel at approximately the same velocity and that the gas follows the ideal gas law, with the density directly proportional to pressure, as

$$
\frac{d U_{z}}{d z}=-U_{G} \frac{d p / d z}{p}
$$

Equation (14) can then be simplified to

$$
\frac{d}{d z}\left(\rho_{c} U_{z}^{2} A_{c}\right)=-\rho_{c} U_{G}^{2} A_{c} \frac{d p / d z}{p}+U_{G} \frac{d W_{L E}}{d z} .
$$

For the special case of equibrium annular flow, where deposition and entrainment rates are equal and the entrainment flow rate is unchanging with distance, the equation for the interfacial shear stress simplifies to

$$
\tau_{i}=-\frac{A_{c}}{P_{C}}\left[\frac{d p}{d z}\left(1-\frac{\rho_{c} U_{G}^{2}}{p}\right)+\rho_{c} g\right]-R_{D}\left(U_{D}-U_{E}\right) \text {. }
$$

\section{CORRELATION OF FRICTION FACTORS}

The interfacial shear stress was calculated for the current set of data, as well as the data of Fore \& Dukler (1995a) and Asali (1984) in order to make the following comparisons and analysis. Table 1 is a brief description of the test section size, geometry and system pressure for the data used from these three studies. The current set of data complements the previous data described in the table through an increase of system pressure and a change of geometry. For both this set of data and the Fore \& Dukler data, only conditions visually observed to be within the disturbance-wave regime of annular flow are used. The disturbance-wave regime is characterized by large waves on the liquid film which travel upward at a relatively constant velocity and can be observed over an appreciable distance. In the film-churning regime, which can occur at lower gas velocities, large liquid lumps exhibit an up-and-down motion on the film and do not travel over a significant distance before disappearing by coalescence or breakup. Due to the different physical behavior, the same mechanisms for interfacial shear stress may not apply to both the disturbance-wave and film-churning regimes.

The pressure gradient and film thickness were measured in all three studies listed in Table 1. The entrained fraction and deposition rate were measured in the current and Fore \& Dukler studies, while only the entrained fraction was measured by Asali. For the Asali data sets, the deposition rate was estimated using Leman's (1985) 
correlation, which was developed from data obtained in the same experimental setup. The entraining droplet velocity, $U_{E}$, was taken as the wave velocity, for the current and Fore \& Dukler studies in which it was measured, and as twice the mean liquid film velocity, for the Asali study. The depositing droplet velocity, $U_{D}$, was taken as $80 \%$ of the mean gas velocity, based on the experimental gas and droplet velocities of Fore \& Dukler (1995b) and Azzopardi \& Teixeira (1994).

Table 1. Data Sets Used for Comparison

\begin{tabular}{|l|l|l|c|c|}
\hline \multicolumn{1}{|c|}{ Study } & \multicolumn{1}{|c|}{$\begin{array}{c}\text { Gas/Liquid } \\
\text { System }\end{array}$} & \multicolumn{1}{|c|}{ Geometry \& Size } & Pressure & Temperature \\
\hline Current & Nitrogen-Water & duct $5.08 \times 101.6 \mathrm{~mm}$ & $3.4 \mathrm{~atm}$ & $38 \& 93^{\circ} \mathrm{C}$ \\
\hline Current & Nitrogen-Water & duct $5.08 \times 101.6 \mathrm{~mm}$ & $17 \mathrm{~atm}$ & $38 \& 93^{\circ} \mathrm{C}$ \\
\hline Fore \& Dukler (1995a) & Air-Water & tube $50.8 \mathrm{~mm}$ & $1 \mathrm{~atm}$ & $18^{\circ} \mathrm{C}$ \\
\hline Fore \& Dukler (1995a) & $\begin{array}{l}\text { Air-50\% } \\
\text { Water/Glycerine }\end{array}$ & tube $50.8 \mathrm{~mm}$ & $1 \mathrm{~atm}$ & $18^{\circ} \mathrm{C}$ \\
\hline Asali (1984) & Air-Water & tube $22.9 \mathrm{~mm}$ & $1 \mathrm{~atm}$ & $\sim 21^{\circ} \mathrm{C}$ \\
\hline Asali (1984) & Air-Water & tube $42 \mathrm{~mm}$ & $1 \mathrm{~atm}$ & $\sim 21^{\circ} \mathrm{C}$ \\
\hline Asali (1984) & Air-Water & tube $42 \mathrm{~mm}$ & $2 \mathrm{~atm}$ & $\sim 21^{\circ} \mathrm{C}$ \\
\hline
\end{tabular}

Figure 3 is a comparison of the data summarized in Table 1 with the original Wallis friction factor shown in Equation (5). Like the original four data sets used to construct this correlation, the friction factors are overpredicted for very small values of the relative film thickness, h/D. However, a simple shift in $h / D$ introduced in the original correlation as

$$
f_{i}=0.005\left[1+300\left(\frac{h}{D}-0.0015\right)\right]
$$

can account for this difference. A justification for this small modification may be that a finite relative film thickness is needed before a significant change to the smooth friction factors is observed. A similar term was included in the Asali, et al. (1985) correlation as outlined below. equations,

Henstock \& Hanratty (1976) fit several sets of friction factor data with the two

$$
\frac{h}{D}=\frac{6.59 F}{\sqrt{f_{i} / f_{G}}}
$$

and

$$
\frac{f_{i}}{f_{G}}=1+1400 F
$$


which can be combined to yield a form similar to the modified Wallis correlation (6) as

$$
f_{i}=f_{G}\left(1+212 \sqrt{\frac{f_{i}}{f_{G}}} \frac{h}{D}\right)
$$

The current set of data and the others listed in Table 1 are compared to this correlation in Figure 4. While the Henstock \& Hanratty correlation reflects the behavior of some of the lower pressure data at large film thicknesses, it severely overpredicts the friction factors at higher pressure.

Asali, et al. (1985) used additional data obtained from Asali (1985) to build a slightly different friction factor correlation as

$$
\frac{f_{i}}{f_{G}}=1+0.45 \operatorname{Re}_{G}^{-0.2}\left(\operatorname{Re}_{G} \sqrt{\frac{f_{i}}{2}} \frac{h}{D}-4\right) .
$$

The constant, 4 , within the parentheses is used to approximate the thickness of the laminar sublayer in wall coordinates. The hypothesis is that only films thicker than the laminar sublayer will increase the interfacial friction factor above the analogous singlephase value. The explicit dependence on the gas Reynolds number in Equation (22) can be removed by using the relationship $f_{G}=0.046 \operatorname{Re}_{G}{ }^{-0.2}$ to yield

$$
f_{i}=f_{G}\left(1+1.46 \times 10^{-7} f_{G}^{-7 / 2} \sqrt{\frac{f_{i}}{f_{G}}} \frac{h}{D}-39.2 f_{G}\right)
$$

which can be compared roughly to the Henstock \& Hanratty correlation by substituting a nominal value of $f_{G}=0.005$ for terms within the parentheses to yield the approximation

$$
f_{i}=f_{G}\left(0.8+161 \sqrt{\frac{f_{i}}{f_{G}}} \frac{h}{D}\right) .
$$

The three sets of data are also compared to this relationship in Figure 4. Like the Henstock \& Hanratty correlation, the Asali, et al. correlation overpredicts the friction factors for large values of the relative film thickness. The agreement is best at low values of $h / D$, which is typical of the Asali (1984) data from which this correlation was developed.

The deviation of the interfacial friction factors from the fully-rough analogy represented by the Wallis correlation was suggested by Lopes \& Dukler (1986) to be an effect of transition roughness. In single-phase flow, friction factors for transitionallyrough flows depend on both the roughness height and on the Reynolds number (cf: Schlichting (1979)). Figure 5 is a plot of the friction factors versus the gas Reynolds number for all of the data used in the above comparisons. Unlike the Lopes \& Dukler result obtained with limited data, one curve cannot be used to represent all of these data. 
In the transition region between smooth and fully-rough pipe flow, the friction factor decreases asymptotically with increasing Reynolds number to the relation shown in Equation (5), which depends only on the relative roughness height. Since a similar decrease with Reynolds number is shown in Figure 5 for annular flow, an interfacial friction factor correlation should also asymptotically approach a value dependent only on the analogous relative roughness height at large gas Reynolds numbers. However, classic friction factor relations for transition and full roughness do not adequately account for the Reynolds number dependence in annular flow. The simple multiplication factor, $\left(1+\mathrm{A} / \mathrm{Re}_{\mathrm{G}}\right)$, has been chosen for inclusion in an improved friction factor correlation to achieve a stronger dependence on the gas Reynolds number. In order to maintain the behavior of the Wallis correlation at small values of the relative film thickness, while incorporating some aspects of transition roughness through this multiplication factor, the new correlation,

$$
f_{i}=0.005\left\{1+300\left[\left(1+\frac{17,500}{\operatorname{Re}_{G}}\right) \frac{h}{D}-0.0015\right]\right\}
$$

has developed. The gas Reynolds number in this equation is based on the core area and perimeter as

$$
\operatorname{Re}_{G}=\frac{\rho_{G} U_{G}\left(4 A_{C} / P_{C}\right)}{\mu_{G}}
$$

which differs slightly from the Reynolds number based on the hydraulic diameter of the conduit due to the reduction in flow area and perimeter by the presence of the liquid film. Analogous to the friction factors in rough pipes, equation (25) produces friction factors which depend only on $h / D$, or roughness by analogy, at large Reynolds numbers by reducing to equation (18) as $\mathrm{Re}_{\mathrm{G}}$ approaches infinity. A comparison with this correlation is shown in Figure 6 with $25 \%$ uncertainty bands. The agreement of all these data, which include more than 200 modern measurements taken in three different experimental studies, is better with this new correlation than with any of the three literature correlations evaluated in Figures 3 and 4.

\section{SUMMARY}

New film thickness and pressure gradient data were obtained in a 5.08 by 101.6 $\mathrm{mm}$ duct for nitrogen and water in annular flow. Pressures of 3.4 and 17 atm and temperatures of 38 and $93^{\circ} \mathrm{C}$ were used to vary the gas density and liquid viscosity. These data were used to compute interfacial shear stresses and interfacial friction factors for comparison with accepted literature correlations. For each of three correlations, those of Wallis (1969), Henstock \& Hanratty (1976) and Asali, et al. (1985), the comparisons were reasonable for small values of the relative film thickness. However, the new data cover conditions not approached by the data used to construct these three literature correlations. By combining the current data with the results of two other comprehensive modern experimental studies, a new correlation for the interfacial friction factor has been developed. This correlation adds elements of transition roughness to Wallis' fully-rough analogy to better predict interfacial friction factors over a wide range of gas Reynolds numbers and liquid film thicknesses. 


\section{NOMENCLATURE}
$A=$ area
$\mathrm{B}_{\mathrm{z}} \quad=\quad$ axial body force per unit volume
$\mathrm{D} \quad=\quad$ tube diameter, hydraulic diameter
$f=$ friction factor
$F=$ Henstock \& Hanratty (1976) parameter
$\mathrm{h}=$ film thickness
$\mathrm{k}_{\mathrm{s}} \quad=\quad$ sand-grain roughness height
$n=$ power law exponent
$\mathrm{p}=$ pressure
$P \quad=\quad$ perimeter
$R_{D}=$ deposition rate
$R_{E}=$ entrainment rate
$\operatorname{Re}=$ Reynolds number
$\mathrm{T}_{\mathrm{z}}=$ axial surface force per unit area
$\mathrm{u}=$ axial velocity
$u^{*} \quad=\quad$ friction velocity
$U$ = average axial velocity
$\mathrm{W}=$ mass flow rate
$y=$ distance from conduit wall
$z=$ axial coordinate
Greek

$\begin{array}{lll}\kappa & = & \text { von Karman constant } \\ \rho & = & \text { density } \\ \tau & = & \text { shear stress }\end{array}$

\section{Subscripts}

$\begin{array}{lll}C & = & \text { centerline, core } \\ D & = & \text { deposition } \\ \mathrm{E} & = & \text { entrainment } \\ \mathrm{G} & = & \text { gas } \\ \mathrm{i} & = & \text { interfacial } \\ \mathrm{L} & = & \text { liquid } \\ \mathrm{LE} & = & \text { liquid entrainment } \\ \mathrm{Z} & = & \text { axial direction }\end{array}$




\section{REFERENCES}

Asali, J. C. (1984) Entrainment in vertical gas-liquid annular flows. PhD Dissertation, University of Illinois.

Asali, J. C., Hanratty, T. J. and Andreussi, P. (1985) Interfacial dag and film height for vertical annular flow. A/ChE J., 31 (6), 895-902.

Azzopardi, B. J, and Teixeira, J. C. F. (1994) Detailed measurements of vertical annular two-phase flow - Part II: Gas core turbulence. Trans. ASME: J. Fluids Eng., 116, 796800 .

Coney, M. W. E. (1973) The theory and application of conductance probes for the measurement of liquid film in two-phase flow. J. Phys. E: Scientific Instruments, 6, 903910.

Fore, L. B. and Dukler, A. E. (1995a) Droplet deposition and momentum transfer in annular flow. AlChE J., 41 (9), 2040-2046.

Fore, L. B. and Dukler, A. E. (1995b) The distribution of drop size and velocity in gasliquid annular flow. Int. J. Multiphase Flow., 21 (2), 137-149.

Gill, L. E., Hewitt, G. F. and Lacey, P. M. C. (1964) Sampling probe studies of the gas core in annular two-phase flow - II: Studies of the effect of phase flow rates on phase and velocity distribution. Chem Eng. Sci., 19, 665-682.

Henstock, W. H. And Hanratty, T. J. (1976) The interfacial drag and the height of the wall layer in annular flows. AlChE J., 22 (6), 990-1000.

Hinze, J. O. (1975) Turbulence. $2^{\text {nd }}$ Ed., McGraw-Hill, New York.

Jayawardena, S. S. (1993) Turbulent flow in the core region of vertical annular gasliquid flow. PhD Dissertation, University of Houston.

Leman, G. W. (1985) Atomization and deposition in two-phase annular flow: Measurement and modeling. PhD Dissertation, University of Illinois.

Lopes, J. C. B. and Dukler, A. E. (1986) Droplet entrainment in vertical annular flow and its contribution to momentum transfer. A/ChE J., 32 (9), 1500-1515.

Moeck, E. O. and Stachiewicz, J. W. (1972) A droplet interchange model for annulardispersed, two-phase flow. Int. J. Heat Mass Transfer, 15, 637-653.

Schlichting, H. (1979) Boundary-layer theory. $7^{\text {th }}$ Ed., McGraw-Hill, New York.

Wallis, G. B. (1969) One dimensional two-phase flow. McGraw-Hill, New York.

Zabaras, G. J. (1985) Studies of vertical annular gas-liquid flows. PhD Diss., University of Houston. 
B-T-3258

Page 16

INTENTIONALLY BLANK PAGE 


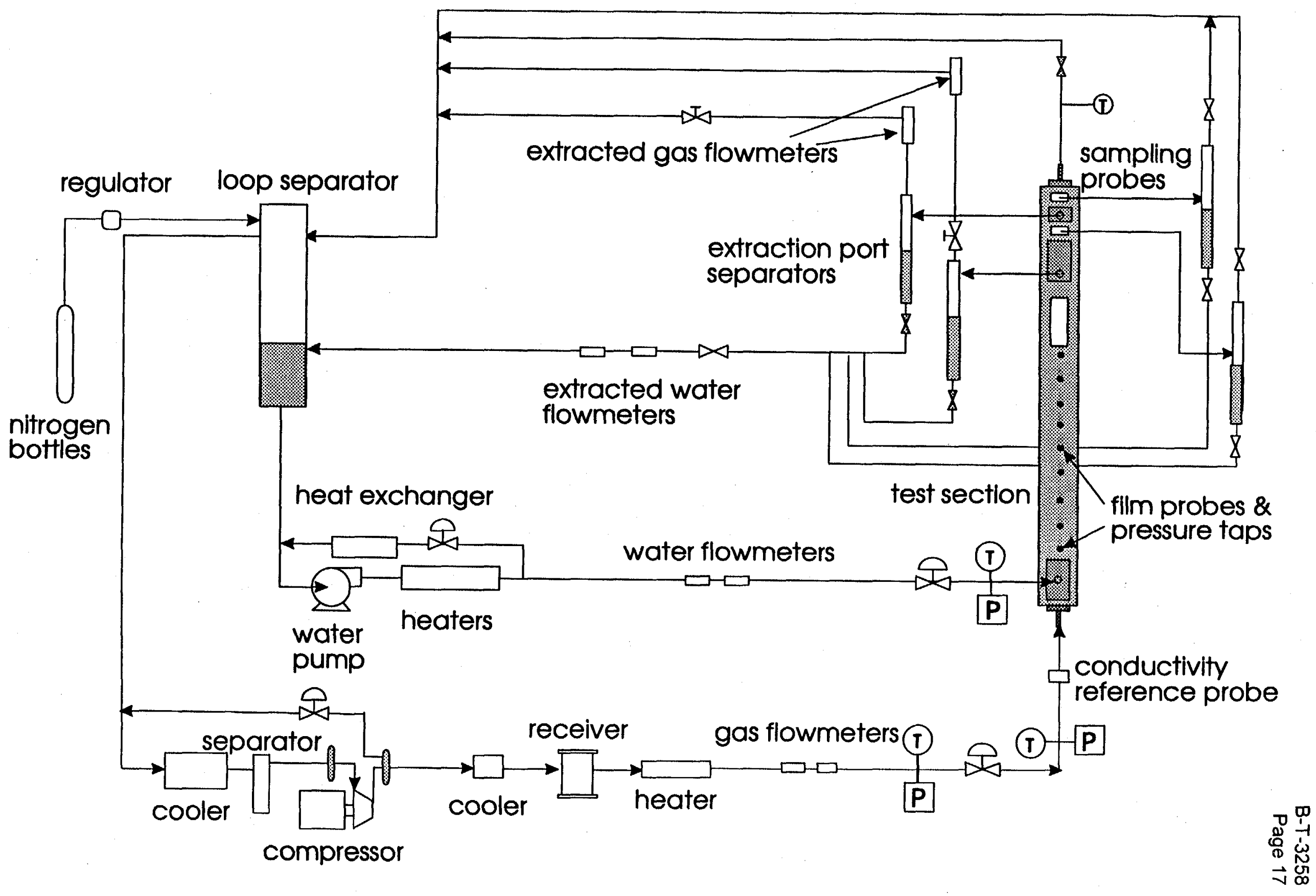

Figure 1. Nitrogen-Water How Loop and Test Section 
Figure 2. Control Volume for Momentum Balance Analysis

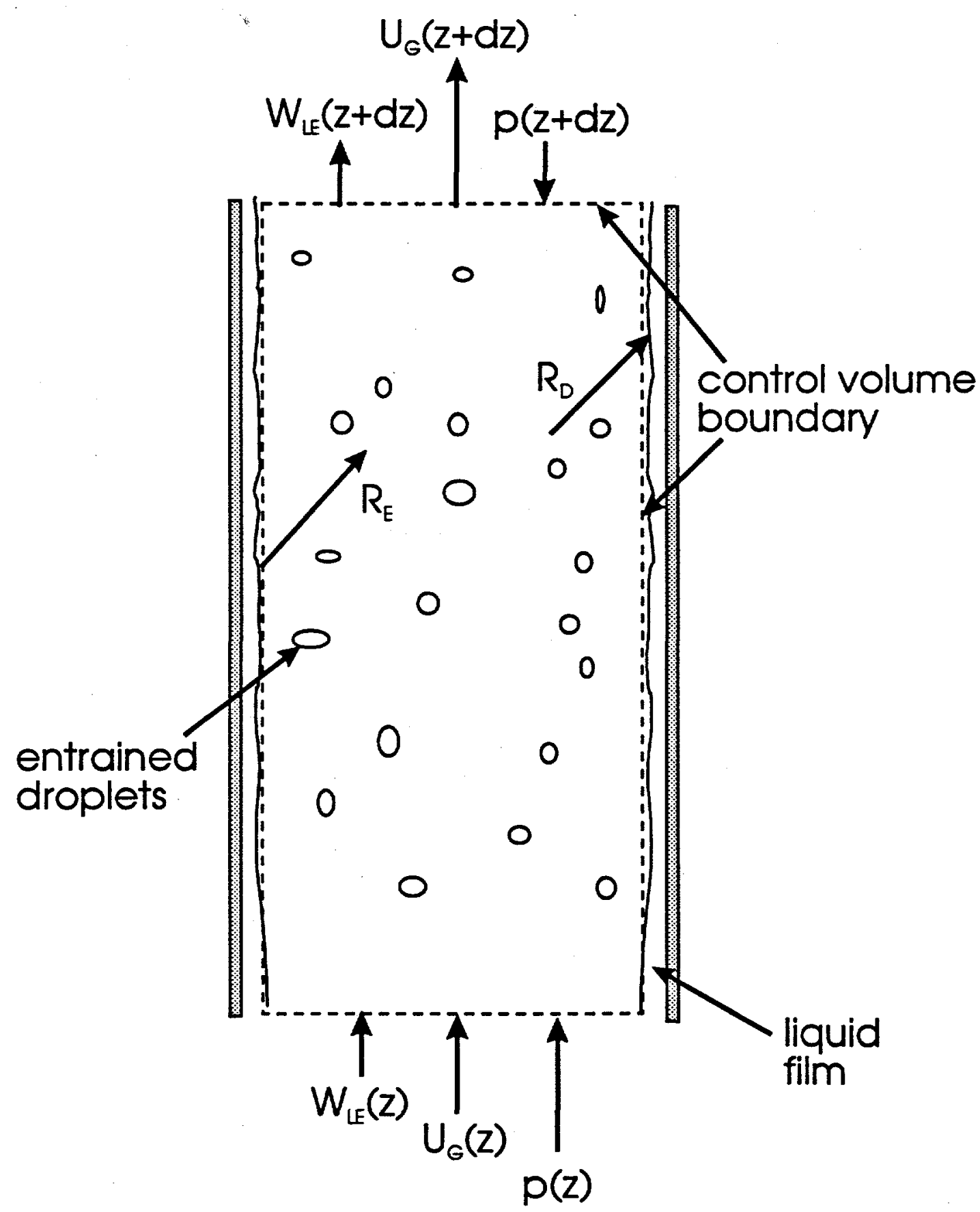




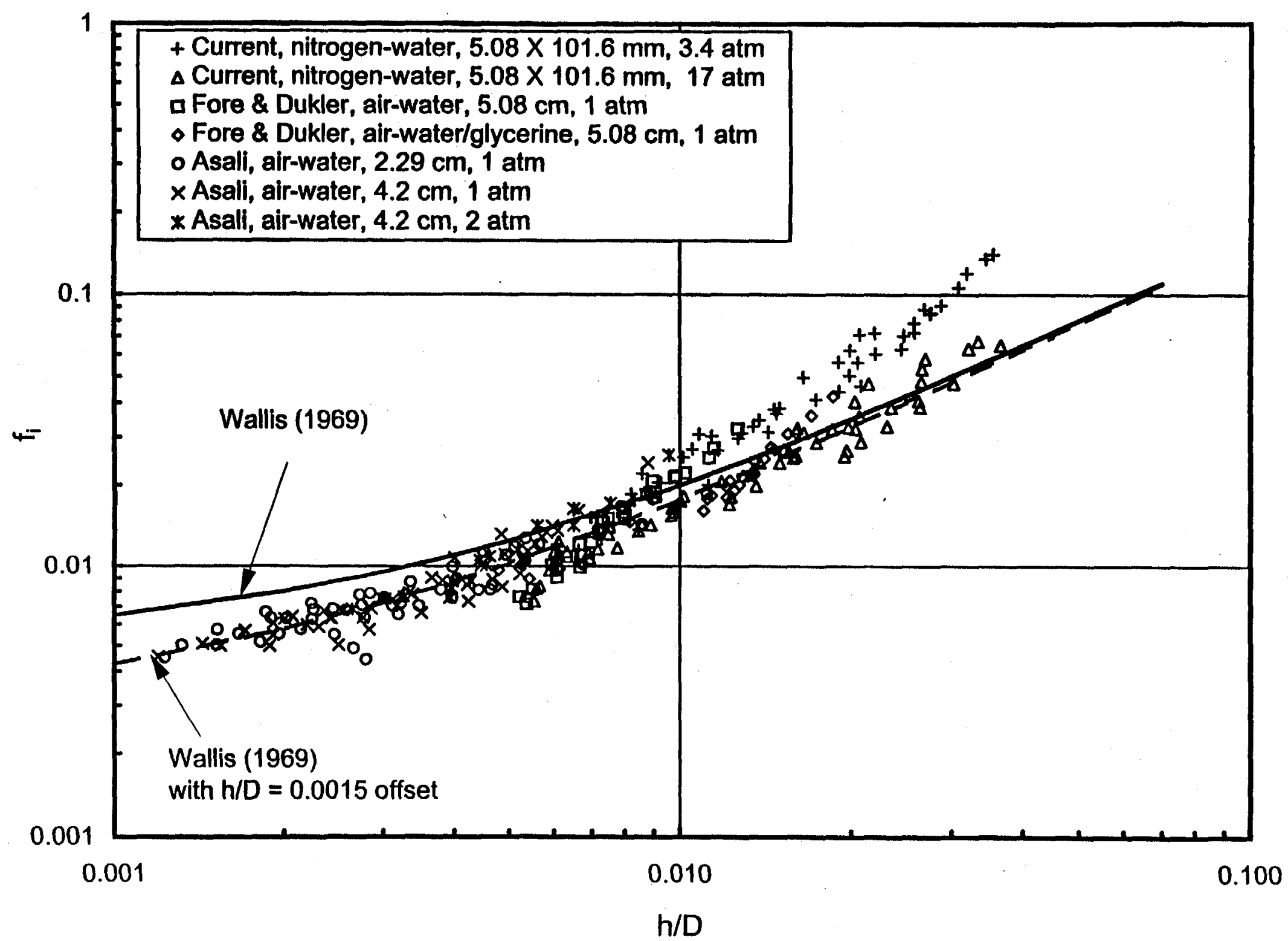

Figure 3. Comparison of Experimental Friction Factors with Wallis (1969) Correlation 


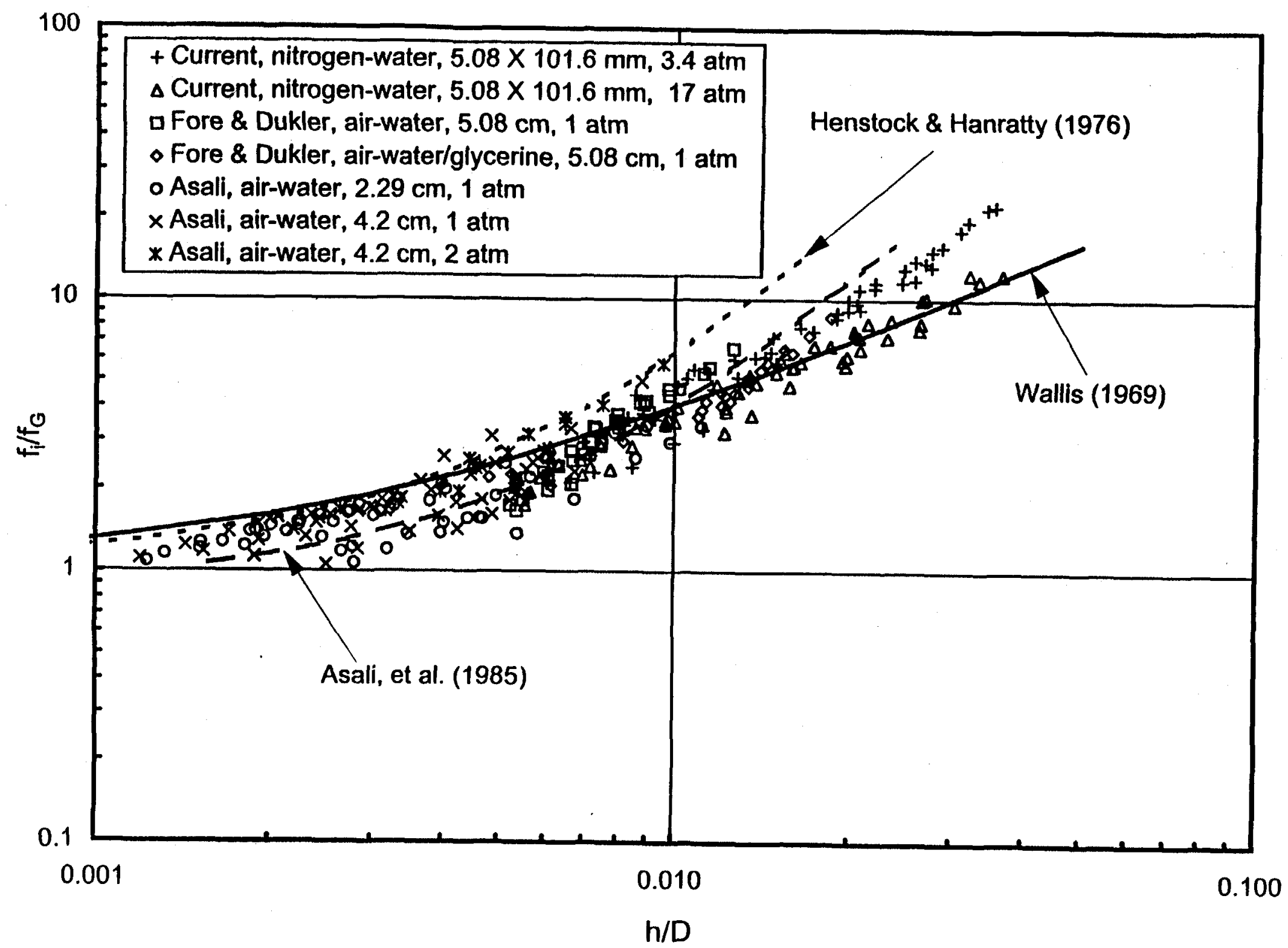

Figure 4. Comparison of Experimental Friction Factors with Henstock \& Hanratty (1976) and Asali, et al. (1985) Correlations 


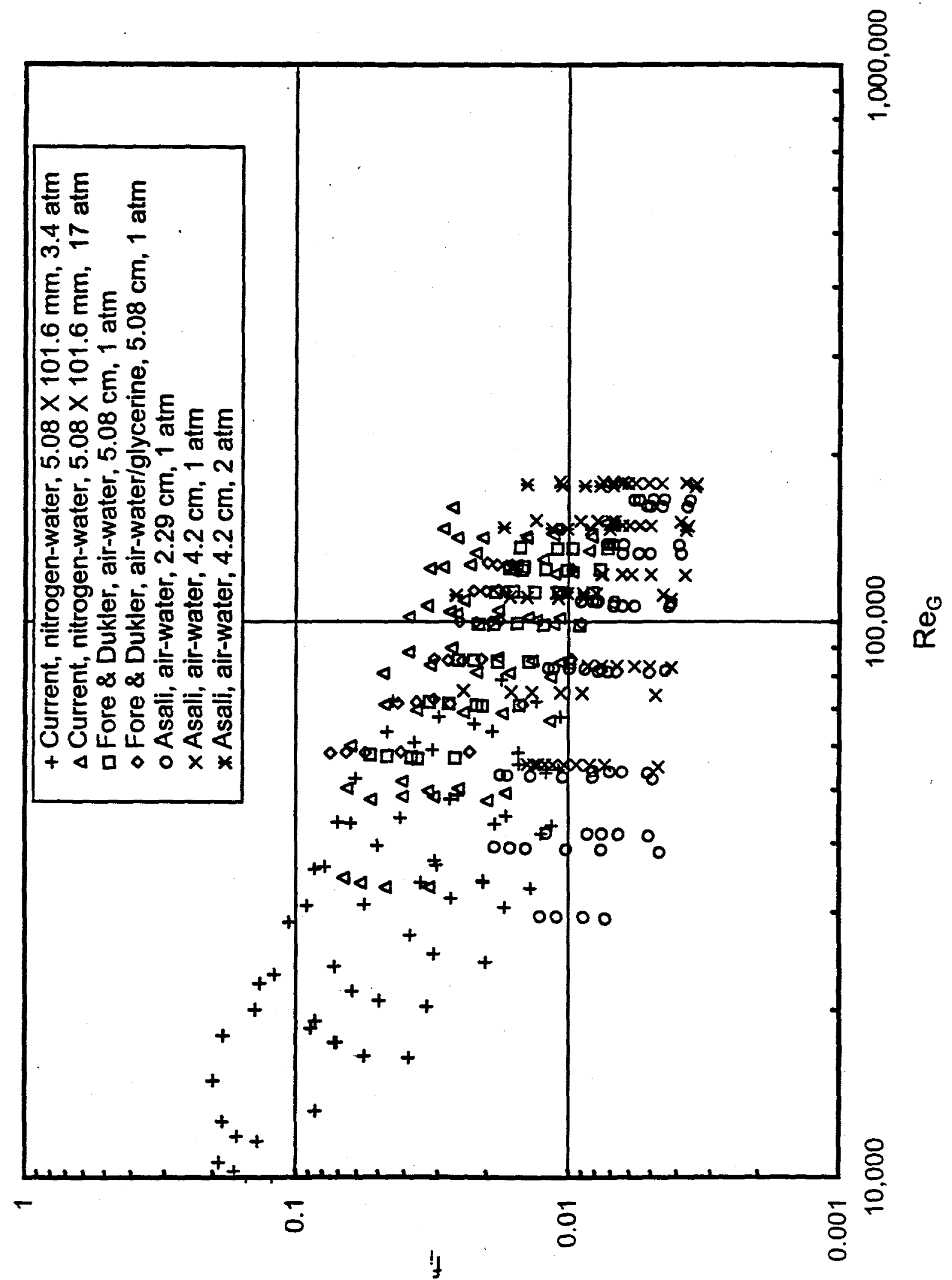




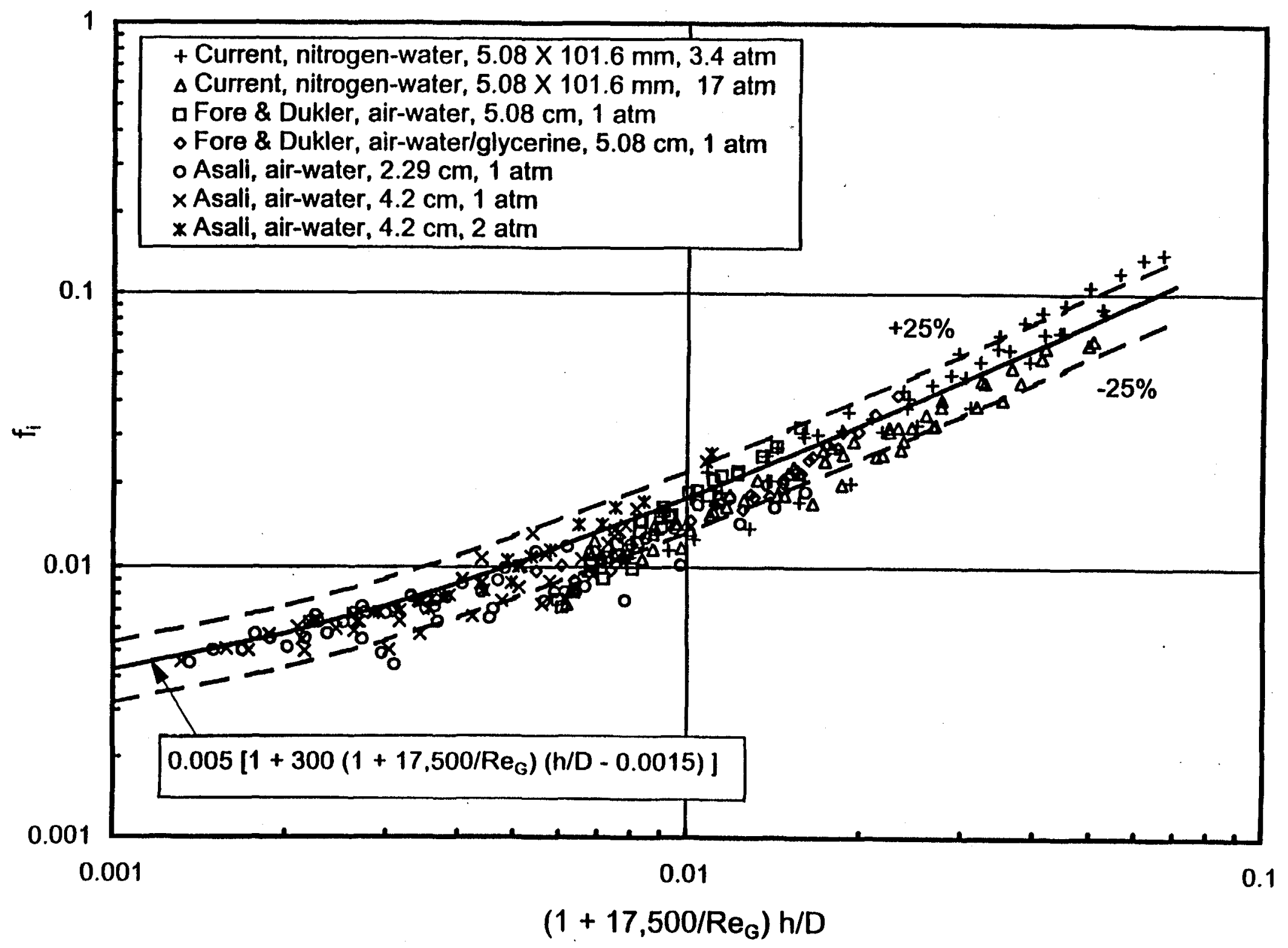

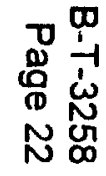

Figure 6. Comparison of Experimental Friction Factors with New Correlation 